\title{
A Study on the Teaching Reform of Basic Courses in Modeling in Higher Vocational Colleges
}

\author{
$\mathrm{Na} \mathrm{Li}$ \\ Department of Art and Design, School of Humanities \\ East China Sea Campus, Yantai Nanshan University \\ Yantai, China \\ e-mail: 284947544@qq.com
}

\begin{abstract}
With the establishment of the objective of training technical talents for application in higher vocational colleges, basic courses centered on drawing and painting in the past can no longer meet the demands of art and design teaching. The author of this paper, based on her own experience in teaching basic courses of art and design, makes a description and analysis of the existing problems in the basic courses of art and design teaching in higher vocational colleges and puts forward the corresponding solutions for the teaching reform. More studies and reforms in basic courses teaching are in desperate need in order to shorten the distance between basic courses and specialized courses in art and design so that basic courses teaching can become an integral part of the art and design teaching system rather than an independent outsider and we can realize the training objectives of art and design teaching and enhance creative thinking and personality development among students.
\end{abstract}

Keywords—art and design; basic courses in modeling; design sketch; thinking training

\section{INTRODUCTION}

The discipline of art and design has been flourishing in higher vocational colleges after its establishment in the field of higher education. The traditional mode of teaching basic courses can no longer meet the requirements of the discipline of art and design, especially for private higher learning institutions that aim to cultivate the innovative spirit and practical abilities of the application-oriented talents. Therefore, it is necessary to explore different ways to reform the teaching of basic courses so as to shorten the distance between the basic courses and specialized courses in design and make basic courses teaching an integral part of the art and design teaching system and a more effective way to realize the training objectives of art and design teaching and enhance personality development and creative thinking among students. The author will make an explanation from the following aspects based on her own teaching experience.

\section{PROBLEMS IN BASIC COURSES TEACHING}

For most people, basic courses in art and design are all about basic training in which modeling training, coloring training and expression training are involved. The basic courses in art and design show almost no difference from the courses taken by students majoring in drawing and painting and get disconnected with the teaching system of the following two years. Students hold the view that basic courses are of little use so that the importance of basic courses teaching is often ignored and the lessons are usually cut. In many colleges, there is only one month for students to attend basic courses, which makes the students unqualified in drawing and painting as well as modeling. Some students only receive basic training for several months before they go to college, so it's very difficult for them to develop their ability of modeling and creative thinking and lay a solid foundation for their future studies in art and design. Besides, at present, both the form and the content of the basic courses teaching in many of the departments of art and design are still traditional. There are also other problems. For example, the teaching aims are not clear enough and the studies on the basic courses in art and design are not systematic.

The students who were born in the 1990s are mostly self-centered. They don't attend the classes that they think are useless or boring, and even the students who attend the class might do things irrelevant. What's more, the primary aim for most students to enter college is to seek a better job, so they pay more attention to the demands of society and become more particular about the curriculum. Thus, students put more emphasis on the specialized courses in artistic design which can produce immediate effects on their studies such as the course of application-oriented software design for computers. They hold the opinion that those application-oriented courses can be more directly, efficiently and rapidly converted into their abilities and qualifications which are useful in their job hunting.

As a result, it is of necessity to connect the basic courses with the specialized courses and to make the the students realize the importance of basic courses.

\section{SOLUTIONS}

First of all, in order to make the students realize the importance of basic courses, we need to reconsider our teaching aims. The author contends that basic courses should lay a solid foundation for the development of creative thinking in design and the expression of the creative thoughts with formal beauty. Such teaching aims are suitable for students majoring in art and design at all levels, which means on the one hand the artistic vision in form and taste of 
fashion of the students should be developed. On the other hand, training of thinking should be included in the basic training.

The pursuit of the principles of formal beauty is the common subject of all disciplines in design. In real life, there exists a common sense of beauty among most people and that common sense comes into existence after a long period of living and producing practice. The basis of that common sense is the objective principles of formal beauty. In the meantime, artistic design has permeated all aspects of life and to some extent it has become a trend-setter. Only if the designer has a vision and a good taste of fashion can he or she creates a good design. All in all, design learning requires that students develop an eye for formal beauty and a taste of fashion, and the phase of basic courses learning is crucial to train and develop the abilities mentioned above.

In the past, basic courses teaching focused on sketching and emphasized the importance of the techniques and exquisiteness of the work. This made the students lazy in thinking. When they were working on their design project, most of them tended to copy the ready-made works. There was little change in their aesthetic taste and thinking after training. However, the purpose of developing the students' vision of formal beauty and taste of fashion as well as training their creative thinking in basic courses is just the opposite. The basic courses are designed to improve the students' artistic qualities and to arouse their awareness to apply the principles of formal beauty in organizing the materials and adjusting the visual effects of the work according to the specific requirements of the project.

Secondly, it usually becomes easier to make adjustments in designing curriculum and arranging classes after we have a general idea of the teaching aims.

\section{A. Adjustments in the Content of Basic Courses}

\section{1) Adjustments in Design Sketch}

The realistic approach of using dark tone as a way of expression has made sketching get disconnected with the teaching system of art and design. Learning how to sketch doesn't just mean learning how to use your hand to describe the forms. Its primary purpose is to develop the students' awareness of modeling and help them learn the proper way of observing. Students should be encouraged to learn art and design through observing different forms in their daily life and making an analysis of the structures and functions of the forms. They should also be able to get a more advanced, detailed and original understanding of the natural, human and abstract forms from the perspectives of nature, science, humanity, society and so on. In teaching practice, sketching by using dark tone should be substituted for design sketch combining creative modeling and expression of sketch. Designing should go before sketching and a work should be judged from its creativeness and design instead of its techniques or whether the realistic approach has been adopted. That is to say, to sketch is not to copy the nature and its primary task is to create models.

Developing the awareness of modeling requires a correct understanding of the basic elements of modeling: form, shape, structure and space. Form is related to the three dimensional measurements of length, width and depth of an object. Cube and cylinder are examples in question. Shape is concerned with the two-dimensional planar graphs with measurements of length and width. There are many ways to grasp the form and shape except for direct sketching. The techniques of perspectives, contrast of light and shadow and contrast of real and imaginary can be used to model the form of the visual objects to produce the real sense of volume and three-dimensional space of the object. Shape can be expressed by abstracting and generalizing the planar dimensions of the image and materializing it into a visual graph. Photographing, copying, rubbing, tearing, burning paper and dribbling are all examples in question. We can easily find those natural shapes in our daily life with careful observation. Two-dimensional space refers to the planar space with length and width composed of the surface of the paper and its four sides. Three-dimensional space is an illusion created in a two-dimensional space in which the length and width as well as the depth of of the object can be perceived. The surface of a piece of paper is planar and it can be imagined as a wall in front. By applying the techniques of perspectives and hues, a "stage" with depth can be built where the beauty of space can be experienced and created on the planar surface of a piece of paper. Structure has something to do with the permutation and combination of the composing elements of an object. For example, human beings and animals are all made up of the basic elements like water, protein and vitamin. However, the differences in the structure, which refers to the permutation and combination of those elements, result in the differences between human beings and animals. The structure of a form mainly refers to its structure in a three-dimensional space. Juxtaposition, mortising and winding are all examples of the structure of a form. Shape is connected with the ways of combination of the planar graphs in a two-dimensional space. The ways of composing a shape are juxtaposition, covering, transparent overlapping, joggling, intertwining and so on. By grasping those ways of composing a structure, a variety of new visual forms can be created.

Besides, deconstruction and reconstruction is also an effective way to create new visual forms. Deconstruction and reconstruction usually means to separate the complete image of an object into several forms or shapes and then re-combine them to create a new form or structure.

Graph is the basic composing element of a design. There are two forms of graph: concrete and abstract. Both forms require creativity. Therefore, it is necessary to adopt the realistic approach of training to model simple graphs. As the core of the teaching reform, courses in training the creativity and expression of abstract graphs should account for a large proportion. For example, the addition and deletion of forms, exaggerated contrast between images and planar segmentation of the background are all included in that kind of training. There shouldn't be too many abstract or imaginary elements and elements characteristic of the specialty should be involved. For example, students specialized in environmental art can add the elements of transparent overlapping in their assignment like simple spiral 
staircases, tall buildings looking from its foot, dislocated space and so on. Students specialized in graphic design can pay special attention to the decoration of the graph and planar patterns can be added. Students specialized in animation can think about different ways to bring changes to the more demanding figure or scene models and to keep the subject in harmony with the background.

Furthermore, students should learn the methods of original modeling and create original forms by making use of the structure and function of natural forms. All the graphs, shapes and images that we use in art and design are forms. There are natural forms, abstract forms and artificial forms. Natural forms are the basis of design. We find our source of creativity by perceiving and analyzing the natural forms. Nature is an amazing creator as an old saying of William Blake's goes, "To see a world in a grain of sand, and a heaven in a wild flower." Plenty of designers are inspired by nature. Students should first collect the natural objects with aesthetic beauty and non-artificial form which are easy to model such as insects, shells, plants and so on. After that the students need to take the initiative to observe and feel the objects by heart. The purpose of observation is to discover the formal beauty and characteristics of objects from their appearance and find inspirations from them. The third step is to sketch. Sketching is the recording of what you have observed and it is also the basis of further changes. Sketching is to understand and grasp the appearance, texture, structure and inner characteristics of the object from different perspectives. Sketching can be conducted to depict the whole object from different angles as well as to depict the most outstanding part of the object. During this, we also need to get a better understanding of the structure and function of the form. The fourth step is to delete, simplify and generalize what we have sketched, highlight the most important part of the object and discard some minor parts. What we should do next is abstracting and transforming. After arranging and improving the form that has been generalized and abstracted, we can use it as an expression of a symbol. We can also deconstruct and reconstruct the form into a new visual image, or we can make an analysis of the structure and function of the natural form, transform it into an artificial form and create a new product. In the last step, we only need to give some tendentious instructions to the students according to their specialties.

\section{2) Adjustments in Color Designing}

Reproducing natural colors is not the teaching aim of the courses in coloring. Courses in coloring are designed to help students master the law of coloring, get an understanding of the characteristics and rules of the relations between colors and other relevant elements. Meanwhile, it is hoped that by learning the courses, students can explain the relations among the physical, emotional and logical aspects of colors and reveal the process of transforming the natural form of color into its artificial form. The traditional realistic approach of training in coloring is typical in drawing and painting instead of designing. In the teaching practice of the courses in coloring, the author substitutes "producing colors" for "designing colors" which is closely related to the formation of colors and the decorative patterns. What's more, from the very beginning, the author has been sticking to the following principles: first, students need to get a rational understanding of the common knowledge and laws of coloring, the different impressions of different colors on people, the emotional characteristics of different colors, the physical properties of colors and the application of colors in daily life; second, students should be able to find as many colors as possible from an object and design those colors by applying the rules of composition, the techniques in decorative pictures and the rules of using patterns; third, training in using hues should be increased, and students should be trained to practice using different hues, improve their controlling ability of colors and get to know the charms of different hues. If students can combine their knowledge of coloring with their specialized courses in their later studies and the principles mentioned above can be followed, naturally, the students' sense of designing can be developed and their fixed thinking mode can be breached.

\section{B. Improvement of Artistic Qualities}

1) Students' aesthetic taste should be improved.

The discipline of art and design belongs to visual arts and it can not be acquired only through the teaching of the courses. Current courses in art appreciation only focus on some classic works of art, so other basic courses should provide opportunities for students to appreciate the excellent works created by other students and teachers and get to know the creating process of the works. It is also a good idea to invite some experienced designers to teach different courses or deliver lectures so that students can learn something unavailable in their textbooks. Only by improving the students' ability of appreciation can they improve their aesthetic taste.

\section{2) The teaching of history of art should be emphasized.}

By learning the history of art and taking nutrients from the excellent human culture, students' theoretical knowledge in art can be enriched. They can know better about the historical backgrounds and social functions of the stylistic changes in art across the historical periods. Learning the history can also broaden the students' horizon and help them to gain new insights and inspirations. For example, traditional Chinese patterns are easy to be found in the masterpieces of the artists. Only by understanding the history of the development of art and the evolution of the styles in art can we know art better and predict the its future trend better.

\section{Emphasis on Experiencing the Designing Process}

The most effective way for students to experience the designing process of art is to assign them art creation tasks. In these tasks, students should be required to combine their theoretical knowledge with their practical abilities and designing methods, and the process and feasibility of these experimental tasks should be emphasized. In the meantime, students should also be trained to reconstruct the knowledge resources, themes, contents, media, structures and techniques concerning the tasks. Moreover, students should also be encouraged to participate in the contests in design at all levels both at home and abroad. In this way, students' interest in design can be further stimulated. 


\section{CONCLUSION}

The teaching reform of basic courses in modeling in higher vocational colleges is becoming more and more urgent. Some colleges have taken measures which prove to be effective. Many other colleges that haven't implemented any reforms should realize the importance and teaching aims of basic courses and make corresponding adjustments to update the contents and methods of basic courses teaching. Only in this way can we meet the requirements of society, connect the basic courses with the specialized courses and develop students' aesthetic taste and creative thinking. More studies and reforms should be conducted in the teaching practice of basic courses. The differences in different specialties should also be taken into consideration. Besides, it is also necessary to shorten the distance between basic courses and specialized courses in design. Basic courses should become an integral part of the teaching system so as to realize the general teaching aims of art and design and develop the students' personality and creative thinking.

\section{REFERENCES}

[1] Lin Jia-yang. Design Sketch [M]. Beijing: Higher Education Press, 2005.

[2] Lin Jia-yang. Color Design [M]. Beijing: Higher Education Press, 2005.

[3] Zhao Yun-chuan, An Jia. A Coursebook on Colors and Sketching [M]. Shenyang: Liaoning Fine Arts Publishing House, 2005. 